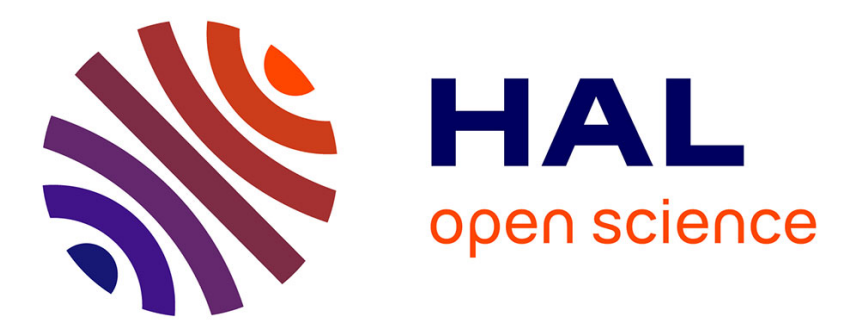

\title{
Sensorless fuzzy sliding mode control for permanent magnet synchronous motor fed by $\mathrm{AC} / \mathrm{DC} / \mathrm{AC}$ converter
}

Fateh Benchabane, Abdenacer Titaouine, Ouafae Bennis, Khaled Yahia, Djamel Taibi

\section{- To cite this version:}

Fateh Benchabane, Abdenacer Titaouine, Ouafae Bennis, Khaled Yahia, Djamel Taibi. Sensorless fuzzy sliding mode control for permanent magnet synchronous motor fed by AC/DC/AC converter. International Journal of Systems Assurance Engineering and Management, 2012, 3 (3), pp.221-229. 10.1007/s13198-012-0111-z . hal-00741877

\section{HAL Id: hal-00741877 \\ https://hal.science/hal-00741877}

Submitted on 18 Oct 2012

HAL is a multi-disciplinary open access archive for the deposit and dissemination of scientific research documents, whether they are published or not. The documents may come from teaching and research institutions in France or abroad, or from public or private research centers.
L'archive ouverte pluridisciplinaire HAL, est destinée au dépôt et à la diffusion de documents scientifiques de niveau recherche, publiés ou non, émanant des établissements d'enseignement et de recherche français ou étrangers, des laboratoires publics ou privés. 


\section{Sensorless fuzzy sliding mode control for permanent magnet synchronous motor fed by $A C / D C / A C$ converter}

\section{F. Benchabane, A. Titaouine, O. Bennis, K. Yahia \& D. Taibi}

International Journal of System Assurance Engineering and Management

ISSN 0975-6809

Int J Syst Assur Eng Manag DOI 10.1007/s13198-012-0111-z
155N 0975-6809

ONLINE FIRST

International Journal of Systems Assurance Engineering and Management

Official Publication of The Society for Reliability Engineering, Quality and Operations Management (SREQOM), India and The Division of Operation and

Division of Operation and Maintenance Engineering Luleå University of Technology, Sweden

\section{L @ פspringer}


Your article is protected by copyright and all rights are held exclusively by The Society for Reliability Engineering, Quality and Operations Management (SREQOM), India and The Division of Operation and Maintenance, Lulea University of Technology, Sweden. This eoffprint is for personal use only and shall not be self-archived in electronic repositories. If you wish to self-archive your work, please use the accepted author's version for posting to your own website or your institution's repository. You may further deposit the accepted author's version on a funder's repository at a funder's request, provided it is not made publicly available until 12 months after publication. 


\title{
Sensorless fuzzy sliding mode control for permanent magnet synchronous motor fed by AC/DC/AC converter
}

\author{
F. Benchabane $\cdot$ A. Titaouine $\cdot$ O. Bennis • \\ K. Yahia - D. Taibi
}

Received: 31 December 2011/Revised: 13 March 2012

(C) The Society for Reliability Engineering, Quality and Operations Management (SREQOM), India and The Division of Operation and Maintenance, Lulea University of Technology, Sweden 2012

\begin{abstract}
In this paper a systematic fuzzy sliding mode controller is presented for permanent magnet synchronous motor (PMSM) sensorless drives. The fuzzy sliding mode controller is designed based on input-output feedback linearization control technique. The extended Kalman filter is used to estimate the speed, position and load torque. The PMSM is fed from indirect power electronics converter. This indirect converter is controlled by the sliding mode technique. This control technique allows the minimization of harmonics introduced by the line converter, including the control of power factor and DC-link voltage. The robustness of the overall system is studied using simulation for different operating modes and varied parameters.
\end{abstract}

Keywords Systematic sliding mode - AC-DC converter . Extended Kalman filter · Sensorless control

\section{Introduction}

Permanent magnet synchronous motors (PMSM) are more and more used because of their good performances. High performance control of the PMSM requires identification of

F. Benchabane $(\bowtie) \cdot$ A. Titaouine $\cdot$ D. Taibi

MSE Laboratory, Department of Electrical Engineering,

University of Biskra, BP 145, Biskra, Algeria

e-mail: fateh_benchabane@yahoo.fr

\section{O. Bennis}

PRISME Institut, University of Orléans, 21 rue Loigny La Bataille, 28000 Chartres, France

K. Yahia

GEB Laboratory, Department of Electrical Engineering, University of Biskra, BP 145, Biskra, Algeria the rotor position which is usually measured by a mechanical rotor position sensor, which increases the cost and the instability of the system. As a result, sensorless control has recently become a research focus (Zheng et al. 2007; Achour et al. 2009).

In this study a fuzzy sliding-mode control system, which combines the merits of the sliding-mode control, the fuzzy inference mechanism and its algorithm, is proposed. In the sliding-mode controller a switching surface that includes an integral operation (Lin and Chiu 1998; Aissaoui et al. 2007) is designed. When the sliding mode occurs, the system dynamic behaves as a robust state feedback control system. Furthermore, in the general sliding-mode control, the upper boundary of uncertainty, which include parameter variations and external load disturbance, must be available. However, the boundary of uncertainty is difficult to determine in advance for practical applications. A fuzzy sliding-mode controller is investigated to resolve this difficulty, in which a simple fuzzy inference mechanism is used to estimate the upper boundary of uncertainty. Furthermore, to reduce the control effort of the sliding-mode controller, the fuzzy inference mechanism is improved by adapting the centres of the membership functions to estimate the optimal boundary of uncertainty (Yu-Sheng and Wang 2009; He and Jiang 2007; Cernat et al. 2000).

In this paper a new state observer based on an extended Kalman filter is proposed. The precis rotor position and speed can be obtained by EKF. Then a sensorless speed control system can be formed. The load torque is used as the feedforward compensation of the reference torque at the output of the speed regulator. With the compensation, the speed fluctuations during load torque impacts can be greatly decreased.

A three-phase converter is used in this work. The power converter can only flow from the utility AC to DC, and the 
line current is not continuous. Because this type of AC-DC conversion does not control line current harmonics, the displacement power factor is poor and the DC side voltage is not constant (Benchouia et al. 2004; Capolino et al. 1992). One remedy is a reversible converter to replace the diode-bridge rectifier and to allow a reversible power line flow which allows the energy recovered from motor-load inertia to be fed back to the utility supply (Benchouia et al. 2004; Grabowski et al. 2000). The DC-link voltage can be regulated by the sliding mode controller.

\section{PMSM model}

With the simplifying assumptions relating to the PMSM, the model of the motor expressed in the Park reference frame is given in the suitable state form (Le Pioufle et al. 1990; Sayeef and Rahman 2007)

$\left\{\begin{array}{l}\dot{X}=F(X)+G \cdot U \\ Y=H(X)\end{array}\right.$

where

$$
\begin{aligned}
& Y(X)=\left[\begin{array}{l}
y_{1}(X) \\
y_{2}(X)
\end{array}\right]=\left[\begin{array}{l}
h_{1}(X) \\
h_{2}(X)
\end{array}\right]=\left[\begin{array}{l}
x_{1} \\
x_{3}
\end{array}\right]=\left[\begin{array}{c}
I_{d} \\
\Omega
\end{array}\right] \\
& X=\left[\begin{array}{l}
x_{1} \\
x_{2} \\
x_{3}
\end{array}\right]=\left[\begin{array}{l}
I_{d} \\
I_{q} \\
\Omega
\end{array}\right] ; U=\left[\begin{array}{l}
V_{d} \\
V_{q}
\end{array}\right] ; G=\left[\begin{array}{cc}
\frac{1}{L_{d}} & 0 \\
0 & \frac{1}{L_{q}} \\
0 & 0
\end{array}\right] \\
& F(X)=\left[\begin{array}{l}
f_{1}(X) \\
f_{2}(X) \\
f_{3}(X)
\end{array}\right]=\left[\begin{array}{l}
a_{1} \cdot x_{1}+a_{2} \cdot x_{2} \cdot x_{3} \\
b_{1} \cdot x_{2}+b_{2} x_{1} \cdot x_{3}+b_{3} \cdot x_{3} \\
c_{1} \cdot x_{3}+c_{2} \cdot x_{1} \cdot x_{2}+c_{3} x_{2}-\frac{T_{l}}{J}
\end{array}\right]
\end{aligned}
$$

and:

$a_{1}=-\frac{R_{s}}{L_{d}} ; a_{2}=\frac{p \cdot L_{q}}{L_{d}} ; b_{1}=-\frac{R_{s}}{L_{q}} ; b_{2}=-\frac{p \cdot L_{d}}{L_{q}}$

$b_{3}=-\frac{p \cdot \phi_{f}}{L_{q}} ; c_{1}=-\frac{f}{J} ; c_{2}=\frac{p \cdot\left(L_{d}-L_{q}\right)}{J} ; c_{3}=\frac{p \cdot \phi_{f}}{J}$

in $f_{1}(X)$ the load torque $T_{l}$ is removed from the state equations and will be considered as a perturbation.

\section{Modeling and control of the boost rectifier}

\subsection{Modeling of the boost rectifier}

The proposed system configuration is shown in Fig. 1.

This circuit will be analyzed under the following assumptions (Hadri-Hamida et al. 2009; Lin 1999)

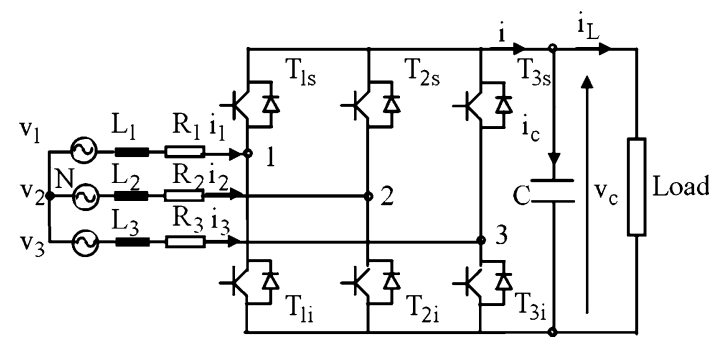

Fig. 1 Rectifier configuration

1. The input AC voltage is a balanced three-phase supply

2. The power switches are ideal

3. All circuit elements are linear and time invariant

The source voltages are assumed to be balanced and they are given by

$v_{1}=V_{m} \cos (\omega t)$
$v_{1}=V_{m} \cos (\omega t-2 \pi / 3)$
$v_{1}=V_{m} \cos (\omega t+2 \pi / 3)$

where $V_{m}$ and $\omega$ are respectively the amplitude of the phase voltage and angular frequency of the power source.

Referring to Fig. 1: By using Kirchhoff's voltage law on the AC side it yields

$L \frac{d}{d t} i_{k}+R i_{k}=v_{k-}\left(v_{k 0}+v_{0 n}\right) k=1,2,3$

where $\mathrm{k}$ indicates $\mathrm{k}$ the phase.

The switching functions $S_{k}$ defined for the $k$ of the converter are given by

$S_{k}=1$ if $T_{k s}$ is on and $T_{k i}$ is off

$S_{k}=0$ if $T_{k s}$ is off and $T_{k i}$ is on

Considering the switching functions $S_{k}$, Eq. (4) can be obtained

$$
\begin{aligned}
& v_{k 0}=v_{c} \quad \text { if } S_{k}=1 \\
& v_{k 0}=0 \quad \text { if } S_{k}=0 \\
& v_{0 N}=-\frac{v_{c}}{3} \sum_{k=1}^{3} S_{k}, \quad k=1,2,3
\end{aligned}
$$

Using the Kirchhoff's current law on the DC side and because of the relations described in Eq. (5), Eq. (6) can be obtained

$$
\begin{aligned}
L \frac{d}{d t} i_{k} & =v_{k}-R i_{k}-S_{k} v_{c}+\frac{v_{c}}{3} \sum_{k=1}^{3} S_{k}, \quad k=1,2,3 \\
C \frac{d}{d t} v_{c} & =\sum_{k=1}^{3} S_{k} i_{k}-i_{L}, \quad k=1,2,3
\end{aligned}
$$

The following state-space model of the rectifier, in the three-phase reference frame, can be obtained by 


$$
\begin{aligned}
\frac{d}{d t}\left[\begin{array}{c}
i_{1} \\
i_{2} \\
i_{3} \\
v_{c}
\end{array}\right]= & {\left[\begin{array}{lllll}
-\frac{R}{L} & 0 & 0 & 0 & 0 \\
0 & -\frac{R}{L} & 0 & 0 & 0 \\
0 & 0 & -\frac{R}{L} & 0 & 0 \\
0 & 0 & 0 & 0 & 0 \\
0 & 0 & 0 & 0 & 0
\end{array}\right]\left[\begin{array}{c}
i_{1} \\
i_{2} \\
i_{3} \\
v_{c}
\end{array}\right] } \\
+ & {\left[\begin{array}{lll}
\frac{-2 v_{c}}{3 L} & \frac{v_{c}}{3 L} & \frac{v_{c}}{3 L} \\
\frac{v_{c}}{3 L} & \frac{-2 v_{c}}{3 L} & \frac{v_{c}}{3 L} \\
\frac{2 v_{c}}{3 L} & \frac{v_{c}}{3 L} & \frac{-2 v_{c}}{3 L} \\
\frac{i_{1}}{C} & \frac{i_{2}}{C} & \frac{i_{3}}{C}
\end{array}\right]\left[\begin{array}{c}
S_{1} \\
S_{2} \\
S_{3}
\end{array}\right] } \\
+ & {\left[\begin{array}{llll}
\frac{1}{L} & 0 & 0 & 0 \\
0 & \frac{1}{L} & 0 & 0 \\
0 & 0 & \frac{1}{L} & 0 \\
0 & 0 & 0 & -\frac{1}{C}
\end{array}\right]\left[\begin{array}{c}
v_{1} \\
v_{2} \\
v_{3} \\
i_{L}
\end{array}\right] }
\end{aligned}
$$

According to the system of Eq. (6) we can say that the main problem in the design of a control law of the boost rectifier is the occurrence of control input function in both AC current $\left(i_{k}\right)$ and DC voltage $\left(v_{c}\right)$ control systems of the converter. Both input functions depend on the same duty ration $S_{k}$ by different dynamic behavior of AC input and DC output of the boost rectifier. Input main voltages and currents should be sinusoidal shaped without phase delay between voltage and current, and output DC voltage should have a constant value by change of voltage dependent current and parameters of the converter (Hadri-Hamida et al. 2009; Jezemik 1999).

\subsection{Sliding mode control of the rectifier}

The block diagram of regulation is illustrated in Fig. 2.

According to Fig. 2, the DC bus voltage error $\left(v_{\text {cref }}-\right.$ $v_{c}$ ) is used to synthesize a line current reference $I_{r e f}$ from a sliding mode controller (SMC). The currents references $i_{1 \text { ref }}, i_{2 \text { ref }}$ are generated from a sinusoidal model obtained through the multiplication of the current reference $I_{\text {ref }}$ by the input voltage, in order to ensure a working with a unity power factor (Hadri-Hamida et al. 2009; Andreescu et al. 2002), the instantaneous and input currents are compared

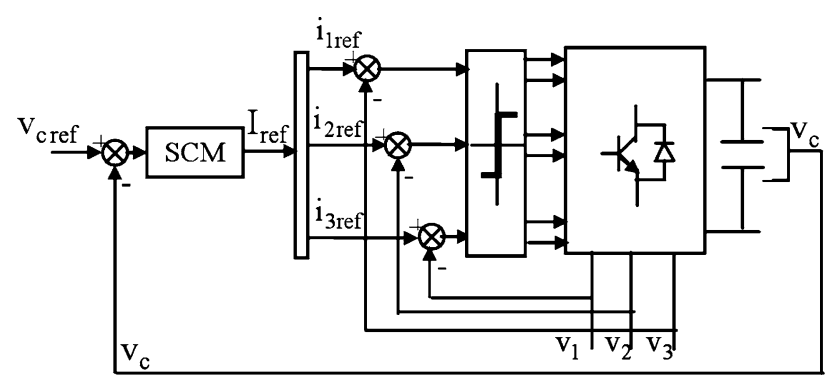

Fig. 2 DC voltage control model with sliding mode controller and the error signals are generated from which the comparators with hysteresis produce switch impulses.

To control the output DC voltage of the rectifier, the SMC can be used (Cernat et al. 2000; Grabowski et al. 2000). Through the sliding surface, the current Iref is given by

$I_{\text {ref }}=K_{c} \cdot \operatorname{sgn}\left(v_{\text {cref }}-v_{c}\right)$

\section{Sliding mode controller design}

The advantages of the sliding mode controller can be summarized as follows (Chung et al. 1999; Goléa 2004)

(1) Fast response with no overshoot

(2) No steady state error

(3) Robustness, stability in a closed loop environment, insensitivity to parameter variations and load disturbances

The switching patterns for a six-pulse inverter are generated directly by the sliding mode. The SMC is designed in $\mathrm{d}-\mathrm{q}$ plane, and the voltages $V_{d}^{*}, V_{q}^{*}$ are taken as control inputs.

The following switching hypersurfaces are used

$S_{1}=I_{\text {dref }}-I_{d}$

$S_{2}=I_{q r e f}-I_{q}$

with $I_{d r e f}=0$.

These selections are based on the concept of vector control and instantaneous current control (Chung et al. 1999; Goléa 2004; Sayed Ahmed et al. 2007). $S_{1}$ and $S_{2}$ are related to inner loop (current loop). In this case, the current components $I_{d}$ and $I_{q}$ are decoupled. The reference currents $I_{\text {dref }}$ and $I_{\text {qref }}$ are determined by the outer loop.

The control inputs are taken as follows

$V_{d}^{*}=K_{d} \operatorname{sign}\left(S_{1}\right)$

$V_{q}^{*}=K_{q} \operatorname{sign}\left(S_{2}\right)$

the gains $K_{d}, K_{q}$ are selected so as to satisfy the existence condition of the sliding mode:

$\lim _{S_{i} \rightarrow 0} S_{i} \dot{S}_{i}<0, \quad i=1,2$

which is equivalent, using the Lyapunov stability, to

$V=\sum_{i=1}^{2} V_{i}$

with

$V_{i}=\frac{1}{2} S_{i}^{2}$

Then, for the control system to be stable, the time derivative of (14) must be negative, i.e. 
$V=\sum_{i=1}^{2} S_{i} \dot{S}_{i}<0$

$K_{d}$ selection: Hence, if we chose $K_{d}$ as

$K_{d}<-\max _{I_{q}, \omega}\left|L_{q} I_{q} \omega\right|$

which yields the following inequality

$S_{i} \dot{S}_{i}<-\frac{R_{s}}{L_{d}} S_{1}^{2}<0$

Only the information about the boundaries of $I_{q}$ and $\omega$ is needed before designing the SMC.

$K_{q}$ selection: Hence, we chose $K_{q}$ as

$K_{q}<-\max _{I_{q r e f}, \omega}\left|R_{s} I_{\text {qref }}+L_{q} \dot{I}_{\text {qref }}+\phi_{f} \omega\right|$

which yields the following inequality

$S_{i} \dot{S}_{i}<-\frac{R_{s}}{L_{q}} S_{3}^{2}<0$

Only the information about the boundaries of $I_{\text {qref }}$ and $\omega$ is needed before designing the SMC.

\section{Fuzzy logic controller}

The general structure of a complete fuzzy control system is given in Fig. 3. The plant control $u$ is inferred from the two state variables, error $(e)$ and change in error $\Delta e$ (Goléa et al. 2002; Senthil Kumar et al. 2008).

The actual crisp inputs are approximates of the closer values of the respective universes of discourse. Hence, the fuzzyfied inputs are described by singleton fuzzy sets.

The design of this controller is based on the phase plan. The control rules are designed to assign a fuzzy set of the control input $u$ for each combination of fuzzy sets of $(e)$ and $\Delta e$ (Chung et al. 1999; Goléa et al. 2002).

Table 1 shows one of possible control rule base. The rows represent the rate of the error change $\dot{e}$ and the columns represent the error $(e)$. Each pair $(e, \dot{e})$ determines the output level NB to PB corresponding to $u$.

Here NB is negative big, NM is negative medium, ZR is zero, $\mathrm{PM}$ is positive medium and $\mathrm{PB}$ is positive big, are

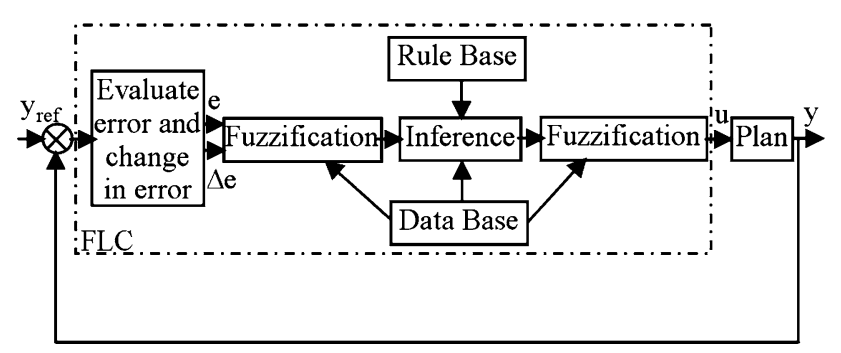

Fig. 3 The structure of a fuzzy logic controller
Table 1 Rules base for speed control

\begin{tabular}{lllllll}
\hline $\mathrm{D}_{\mathrm{u}}$ & & $\mathrm{DE}_{\mathrm{n}}$ & & & & \\
\cline { 3 - 6 } & & $\mathrm{NB}$ & $\mathrm{NM}$ & $\mathrm{ZR}$ & $\mathrm{PM}$ & $\mathrm{PB}$ \\
\hline $\mathrm{E}_{\mathrm{n}}$ & $\mathrm{NB}$ & $\mathrm{NB}$ & $\mathrm{NB}$ & $\mathrm{NM}$ & $\mathrm{NM}$ & $\mathrm{ZR}$ \\
& $\mathrm{NM}$ & $\mathrm{NB}$ & $\mathrm{NM}$ & $\mathrm{NM}$ & $\mathrm{ZR}$ & $\mathrm{PM}$ \\
& $\mathrm{ZR}$ & $\mathrm{NM}$ & $\mathrm{NM}$ & $\mathrm{RZ}$ & $\mathrm{PM}$ & $\mathrm{PM}$ \\
& $\mathrm{PM}$ & $\mathrm{NM}$ & $\mathrm{ZR}$ & $\mathrm{PM}$ & $\mathrm{PM}$ & $\mathrm{GP}$ \\
& $\mathrm{PB}$ & $\mathrm{ZR}$ & $\mathrm{PM}$ & $\mathrm{PM}$ & $\mathrm{GP}$ & $\mathrm{GP}$ \\
\hline
\end{tabular}

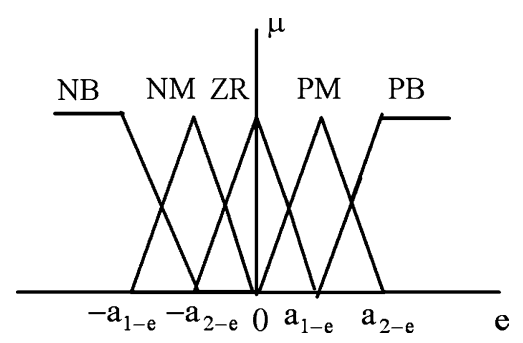

Fig. 4 Membership functions for input e

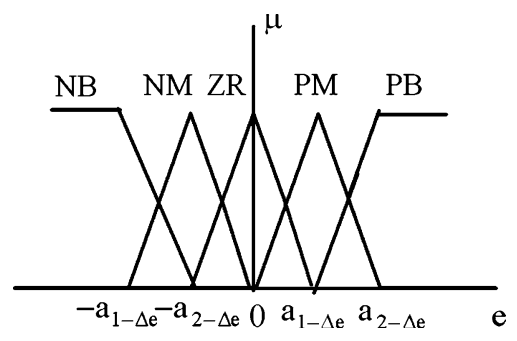

Fig. 5 Membership functions for input $\Delta \mathrm{e}$

labels of fuzzy sets and their corresponding membership functions are depicted in Figs. 4, 5 and 6, respectively.

The continuity of input membership functions, reasoning method, and defuzzification method for the continuity of the mapping $u_{f u z z y}(e, \dot{e})$ is necessary. In this paper, the triangular membership function, the max-min reasoning method, and the center of gravity defuzzification method are used, as those methods are most frequently used frequently in the literature (Goléa et al. 2002; Senthil Kumar et al. 2008).

\section{Design of EKF observer}

Accurate and robust estimation of motor variables which are not measured is crucial for high performance sensorless drives. A multitude of observers have been proposed, but only a few are able to sustain persistent and accurate wide speed range sensorless operation. At very low speed, their performances are poor. One of the reasons is the high 


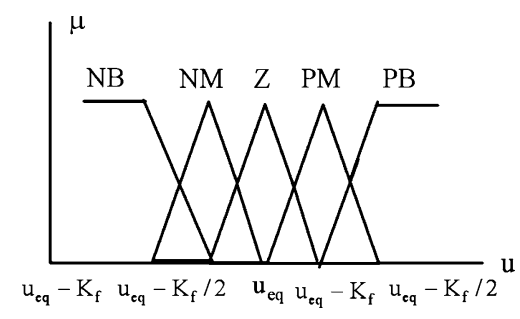

Fig. 6 Membership functions for output u

sensitivity of the observers to unmodeled nonlinearities, disturbance and model parameters detuning.

The Kalman filter provides a solution that directly cares for the effects of disturbance noises including system and measurement noises. The errors in parameters will also normally be handled as noise (Janiszewski 2006).

The dynamic state model for non non-linear stochastic machine is as follows where all symbols in the formulations denote matrices or vectors (Sayed Ahmed et al. 2007; Janiszewski 2006)

$\left\{\begin{array}{l}\dot{x}(t)=f(x(t), u(t), t)+w(t) \\ y(t)=h(x(t), t)+v(t)\end{array}\right.$

$w(t)$ : System noise vector

$v(t)$ : Measurement noise vector

$w, v$ : are unrelated and zero mean stochastic processes

A recursive algorithm is presented for the discrete time case. For the given sampling time $T_{s}$, both the optimal estimate sequence $x_{k / k}$ and its covariance matrix $P_{k / k}$ generated by the filter go through a two step loop.

The first step (prediction) performs a prediction of both quantities based on the previous estimates $x_{k-1 / k-1}$ and the mean voltage vector actually applied to the system in the period from $T_{k-1}$ to $T_{k}$. F is the system gradient matrix (Jacobean matrix).

$F(\tilde{x}(t), t)=\left.\frac{\partial f(x(t), u(t), t)}{\partial x^{T}(t)}\right|_{x(t)=\tilde{x}(t)}$

$x_{k / k-1}=x_{k-1 / k-1}+T_{s} . f\left(x_{k-1 / k-1}, u_{k-1}\right)$

$P_{k / k-1}=P_{k / k-1}+\left(F P_{k-1 / k-1}+P_{k-1 / k-1} F^{T}\right) \cdot T_{s}+Q$

The second step (innovation) corrects the predicted state estimate and its covariance matrix trough a feedback correction scheme that makes use of the actual measured quantities; this is realized by the following recursive relations:

$x_{k / k}=x_{k / k-1}+K_{k}\left(Y_{k}-H x_{k / k-1}\right)$

$P_{k / k}=P_{k / k-1}-K_{k} H P_{k / k-1}$

Where the filter gain matrix is defined by:

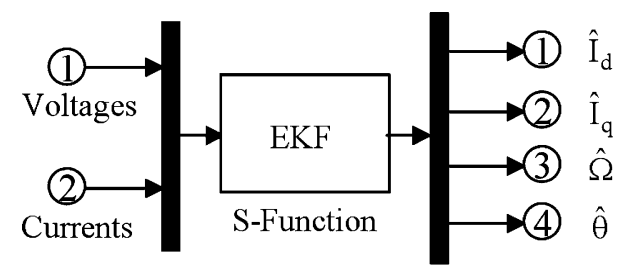

Fig. 7 S-Function representation of the EKF

$k_{k}=P_{k / k-1} H^{T}\left(H P_{k / k-1} H^{T}+R\right)^{-1}$

$\mathrm{H}$ is transformation matrix.

$H(\tilde{x}(t), t)=\left.\frac{\partial h}{\partial x}\right|_{x(t)=\tilde{x}(t)}$

The proposed EKF observer is designed in rotor reference frame ( $d, q$ frame). given by Fig. 7 .

The state vector is chosen to be

$X=\left[\begin{array}{llll}I_{d} & I_{q} & \Omega & \theta\end{array}\right]^{T}$

Input $U=\left[V_{d} V_{q}\right]^{T}$

Output $Y=\left[I_{d} I_{q}\right]$

$I_{d}, I_{q}$ and $V_{d}, V_{q}$ are motor stator currents, voltages in rotor reference frame.

The critical step in the EKF is the search for the best covariance matrices $\mathrm{Q}$ and $\mathrm{R}$ have to be set-up based on the stochastic properties of the corresponding noise. The noise covariance $\mathrm{R}$ accounts for the measurement noise introduced by the current sensors and quantization errors of the A/D converters (Sayed Ahmed et al. 2007; Janiszewski 2006). Increasing $R$ indicates stronger disturbance of the current. The noise is weighted less by the filter, causing also a slower transient performance of system.

The noise covariance $\mathrm{Q}$ reflects the system model inaccuracy, the errors of the parameters and the noise introduced by the voltage estimation (Sayed Ahmed et al. 2007; Janiszewski 2006). Q has to be increased at stronger noise driving the system, entailing a more heavily weighting of the measured current and a faster transient performance.

An initial matrix $P_{0}$ represents the matrix of the covariance in knowledge of the initial condition. Varying $P_{0}$ affects neither the transient performance nor the steady state condition of the system. In this study, the value of these elements is tuned "manually", by running several simulations. This is maybe one of the major drawbacks of the Kalman filter.

The blocks FSMC (fuzzy sliding-mode control), SMC (sliding-mode control) are regulators, the first controller for speed, and the second is the sliding mode control regulator for rectifier. 


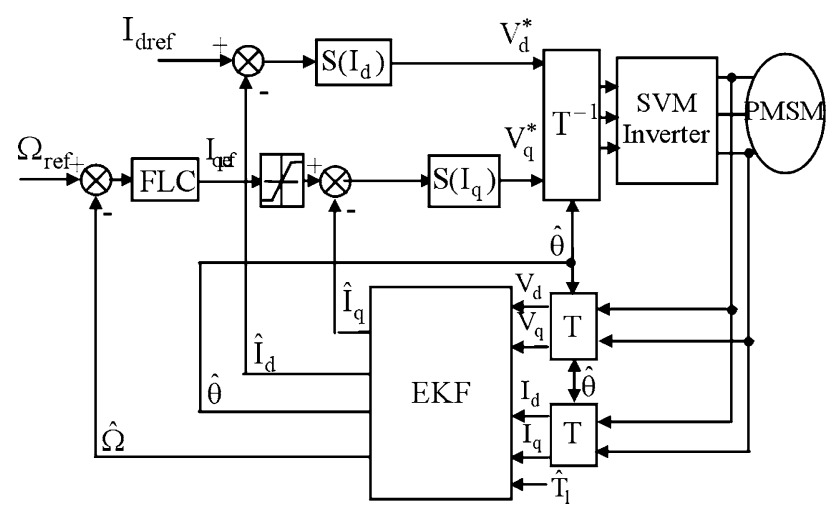

Fig. 8 Speed control of a PMSM using the fuzzy sliding mode with an EKF for speed and position estimation

Figure 8 shows the proposed Sensorless fuzzy slidingmode control using EKF. In this study, the outputs of a PWM voltage source inverter are used as the control inputs for the EKF. These signals contain components at high frequencies, which are used as the required noise by the Kalman filter. Thus, no additional external signals are then needed.

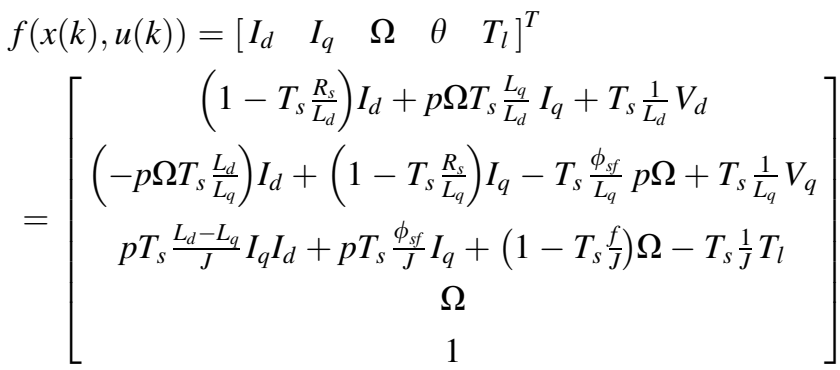

where $h=\left[\begin{array}{ll}I_{d} & I_{q}\end{array}\right]^{T}$

\section{Load torque estimation}

The load torque is not easily measurable so it has to be estimated. The method suggested by Le Pioufle allows estimating it in real-time (Le Pioufle et al. 1990). Figure 9 illustrates the principle for estimation and The responses illustrate high performances of the proposed method is given by Fig. 10 .

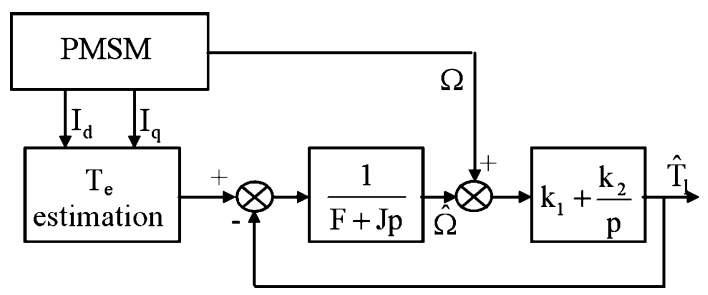

Fig. 9 Estimation of load torque
The error between measured speed and estimated speed is presented like the entry of the PI regulator

$\hat{T}_{l}=\frac{1+\frac{k_{1}}{k_{2}} P}{1+\frac{1+k_{1}}{k_{2}} P+\frac{1}{k_{2}} P^{2}} T_{l}$

$k_{1}$ et $k_{2}$ are determined by poles imposition.

\section{Chattering problem}

The sliding mode control (SMC) has been successfully introduced by (Utkin 1974) and its application by Bosg (1985). It has been known that sliding mode techniques generate unexpected chattering (Sayed Ahmed et al. 2007; Chi and Xu 2006; Lin and Fung 1998).

A natural solution is to attempt to smoothen the discontinuity in the signum function to obtain an arbitrary close hut continuous approximation. In these experimental investigations (Sayed Ahmed et al. 2007; Lin and Fung 1998; Zhuang and Rahman 2003) some suitable continuous switching functions were introduced. In this paper, the following continuous switching function is used:

$\operatorname{Sign}\left(\mathrm{S}_{\mathrm{i}}\right)= \begin{cases}+1, & \text { if } \mathrm{S}_{\mathrm{i}}>\lambda \\ -1, & \text { if } \mathrm{S}_{\mathrm{i}}<-\lambda \\ \frac{\mathrm{S}_{\mathrm{i}}}{\lambda}, & \text { if } \mathrm{S}_{\mathrm{i}}<-\lambda\end{cases}$

where $\lambda_{\mathrm{i}}>0$, is a smooth factor.

Simulation results using the sliding mode control strategy with different non linear control $U_{n}$ are given. Figure 11 shows the step response of speed equals $200 \mathrm{rad} / \mathrm{s}$ and at $0.2 \mathrm{~s}$ a rating load of $5 \mathrm{Nm}$ was applied. We can notice the generation of unexpected chattering in the responses of speed and electromagnetic torque.

To solve the chattering problem, the sign function is replaced by a continuous function as shown in Fig. 12. We can notice the good performances using continuous function $\mathrm{U}_{\mathrm{n}}$, the speed control converges to the reference one with a high precision. It can concluded that the electromagnetic torque developed by the motor increased at $\mathrm{t}=0.2 \mathrm{~s}$ to $5 \mathrm{Nm}$ in order to compensate the load torque. The speed and electromagnetic torque allures are approximately free from high frequency oscillations (chattering).

\section{Simulation results}

\subsection{Simulation results of SMC rectifier}

The simulation conditions are given in the appendix.

In order to demonstrate the feasibility of the proposed control method, the system depicted in Fig. 1 has been 
Fig. 10 Simulation results of load torque estimation
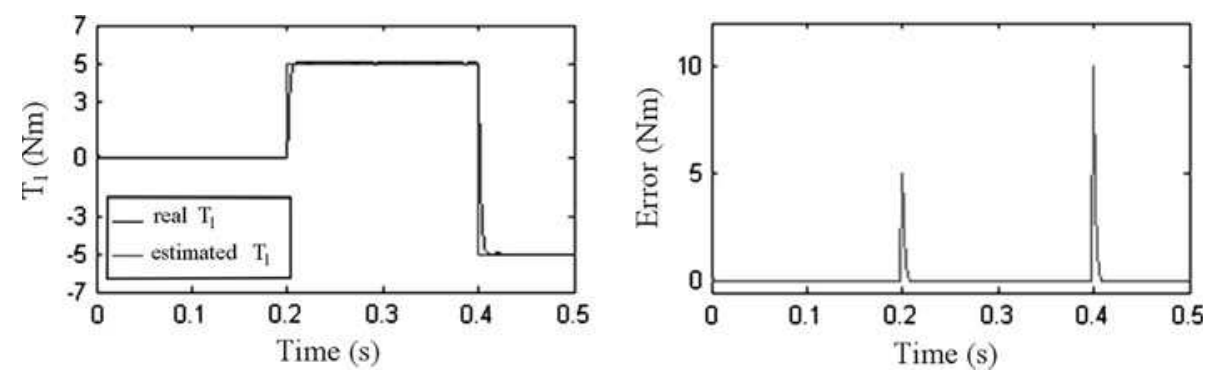

Fig. 11 Simulation results in the case of sign function

Fig. 12 Simulation results in the case of continuous function

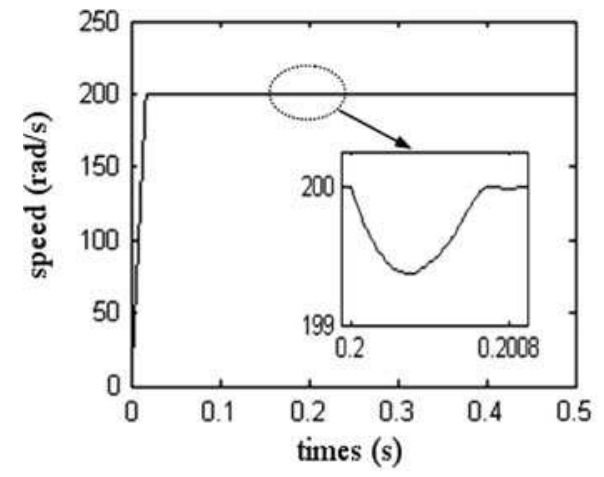

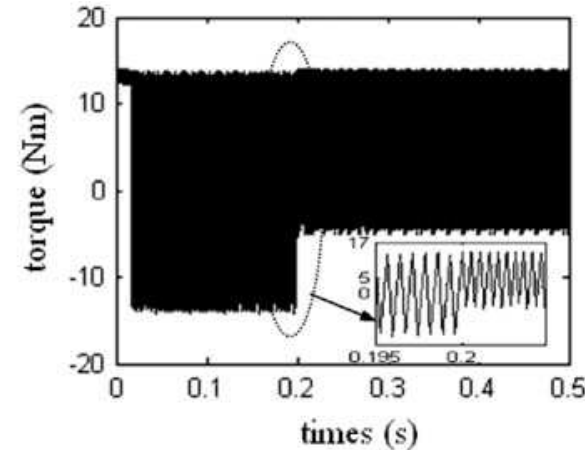

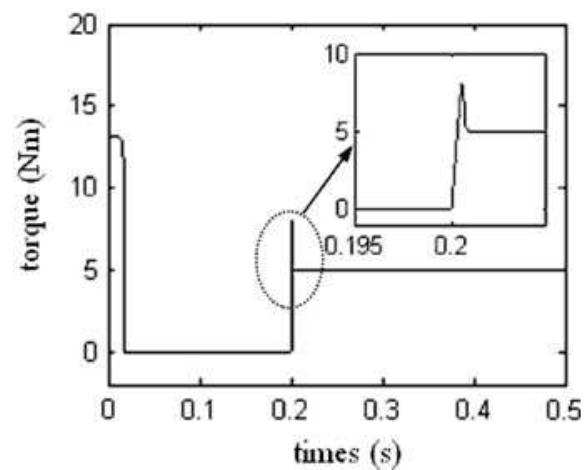

simulated. Figure 13 shows that the output voltage of the rectifier is well controlled to $440 \mathrm{v}$. Therefore, the output DC voltage response is completely robust with the unity power factor at the AC side of the boost rectifier.

Simulation results obtained were in good performance as it is expected. The strategy control was very robust to uncertain parameters and gave a very high power factor and small ripple in the current line supply.

\subsection{Simulation results of sensorless fuzzy sliding-mode control for PMSM}

Extensive simulations have been performed using Matlab/ Simulink Software to examine the control algorithm of the sensorless fuzzy sliding-mode control applied for PMSM presented in Fig. 8 and based on $3 \mathrm{Kw}$ motor parameters.

Figure 14 shows the responses of speed, position, currents and load torque with errors between the actual and

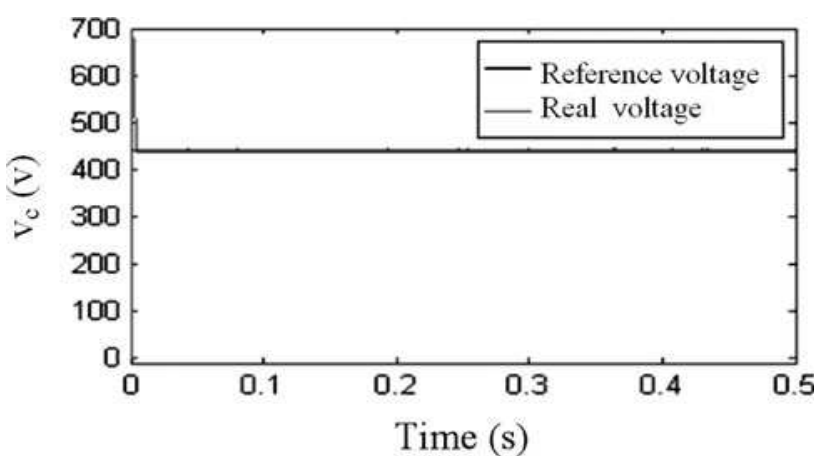

Fig. 13 Simulation results of the rectifier output voltage

estimated states for step reference with $75 \%$ of rated load at $\mathrm{t}=0.1 \mathrm{~s}$. At $\mathrm{t}=0.2 \mathrm{~s}$ the speed is reversed from $+100 \mathrm{rad} / \mathrm{s}$ to $-100 \mathrm{rad} / \mathrm{s}$ and at $\mathrm{t}=0.4 \mathrm{~s}$ the reference speed becomes $10 \mathrm{rad} / \mathrm{s}$. 
Fig. 14 Drive response under reference speed inversion under load disturbances
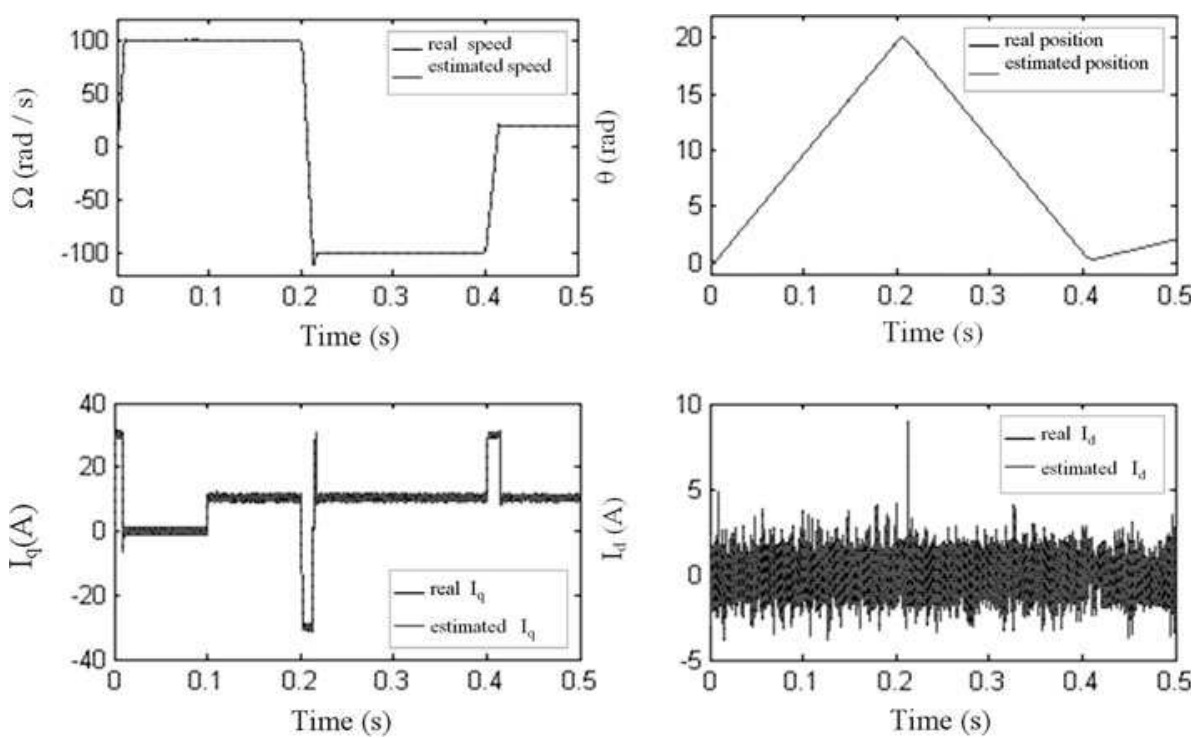

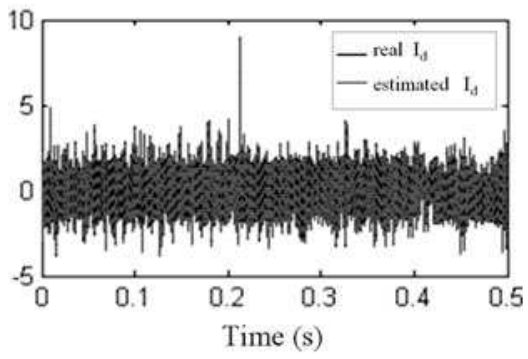

These responses illustrate high performances of the proposed EKF observer combined with nonlinear controller during transient and steady states and the EKF works at very low speed, where many speed estimators or observers perform poorly.

\section{Conclusion}

We have implemented and simulated the fuzzy sliding mode control of a permanent magnet synchronous motor, The dynamic behavior and the control performances obtained are satisfactory. The perturbation is rejected.

For the rectifier, performances of the SMC are evaluated through the simulation of his model. The obtained results show the efficiency and the precision of this control.

The observer based on an extended Kalman filter can observe the exact rotor speed, position and load torque. The EKF observer is able to increase the performance of the fuzzy sliding mode control in terms of low speed behavior, speed reversion and load rejection.

\section{Appendix}

Parameters of the system used in simulation

Parameters of the PMSM:

Rated power $1 \mathrm{kw}$

Rated speed $3000 \mathrm{rpm}$

Stator winding resistance $0.6 \Omega$

Stator winding direct inductance $4 \mathrm{mH}$

Stator winding quadrate inductance $2.8 \mathrm{mH}$

Rotor flux $0.12 \mathrm{~Wb}$

Viscous friction $1.4 \mathrm{e}^{-3} \mathrm{Nm} / \mathrm{rad} / \mathrm{s}$
Inertia $1.1 \mathrm{e}^{-3} \mathrm{~kg} \mathrm{~m}^{2}$

Pairs pole number 4

Nominal current line $20 \mathrm{~A}$

Nominal voltage line $310 \mathrm{~V}$

Machine type: Siemens 1FT6084-8SK71-1TGO

Parameters of the PWM converter

Supply's voltage and frequency: $220 \mathrm{~V}(\mathrm{rms}), 50 \mathrm{~Hz}$

Line's inductor and resistance $0.002 \mathrm{H}, 0.08 \Omega$

Output capacitors $0.0025 \mathrm{~F}$

PWM carrier frequency $1 \mathrm{kHz}$

\section{References}

Achour AY, Mendil B, Bacha S, Munteanu I (2009) Passivity-based current controller design for a permanent-magnet synchronous motor. ISA Trans 48(3):336-346

Aissaoui AG, Abid M, Abid H, Tahour A, Zeblah AK (2007) A fuzzy logic controller for synchronous machine. J Electr Eng 58(5): 285-290

Andreescu GD, Popa A, Spilca A (2002) Two sliding mode based observers for sensorless control of PMSM drives. Electr Power Compon Syst 30(2):121-133

Benchouia MT, Zouzou SE, Golea A, Ghamri A, (2004) Modeling and simulation of variable speed system with adaptive fuzzy controller application to PMSM. In IEEE international conference on industrial technology ICIT, vol 2, pp 683-687

Bosg BK (1985) Sliding mode control of inuctioii motor. In: IEEE international conference

Capolino GA, Goléa A, Hénao H (1992) Modélisation et simulation d'un asservissement à vitesse variable avec mode glissant, Journées d'études Avertissement Electromécaniques Rapides. Modélisation et Régulation Avancées, Metz

Cernat M, Comnac V, Cotorogea M, Korondi P, Ryvkin S, Cernat RM (2000) Sliding mode control o4f interior permanent magnet synchronous motors. In: VII IEEE international power electronics congress, Acapulco, MEXICO, pp 48-53 
Chi S, Xu L (2006) Sliding mode sensorless control of PM synchronous motor for direct-driven washing machines. In: IEEE international conference on industry applications, pp 873-879

Chung S-K, Bae J-D, Youn M-J (1999) Integral variable structure controller for current control of PWM inverter-fed AC drives. Electr Power Compon Syst 27(7):753-769

Goléa A (2004) Systematic sliding mode approach to permanent magnet synchronous drive control, 1ére Conference Nationale sur 1'Electrotechnique et ses Applications, Sidi Bel-Abbés, Conference Publication, pp 37-41

Goléa N, Goléa A, Benmahammed K (2002) Fuzzy model reference adaptive control. IEEE Trans Fuzzy Syst 10(4):436-444

Grabowski PZ, Kazmierkowski MP, Bose BK, Blaabjerg F (2000) A simple direct-torque neuro-fuzzy control of PWM-inverterfedinduction motor drive. IEEE Trans Indus Electron 47:863-870

Hadri-Hamida A, Allag A, Hammoudi MY, Mimoune SM, Zerouali S, Ayad MY, Becherif M, Miliani E, Miraoui A (2009) A nonlinear adaptive backstepping approach applied to a three phase PWM AC-DC converter feeding induction heating. Commun Nonlinear Sci Numer Simul 14(4):1515-1525

He YY, Jiang W (2007) A new variable structure controller for direct torque controlled interior permanent magnet synchronous motor drive. In: Proceedings of the IEEE international conference on automation and logistics, pp 2349-2354

Janiszewski D (2006) Extended Kalman filter based speed sensorless PMSM control with load reconstruction. In: The 23nd annual conference of the IEEE industrial electronics society, pp 1465-1468

Jezemik K (1999) VSS control of unity power factor. IEEE Trans Industr Electron 46:325-332

Le Pioufle B, Georgiou G, Louis JP (1990) Application des commandes non linéaires pour la régulation en vitesse ou en position de la machine synchrone autopilotée. Rev Phys Appl 25:517-526
Lin BR (1999) High power factor AC/DC/AC converter with random PWM. IEEE Trans Aerosp Electron Syst 35:935-943

Lin FJ, Chiu SL (1998) Adaptive fuzzy sliding-mode control for PM synchronous motor drives. IEE Proc Control Theory Appl 145(1): 63-72

Lin F-J, Fung R-F (1998) Comparison of sliding-mode and fuzzy neural network control for motor-toggle servomechanism. IEEE Trans Mechatron 3:302-318

Sayed Ahmed MS, Ping Z, Wu YJ (2007) Modified sliding mode controller with extended Kalman filter for stochastic systems. In: IEEE international conference on control and automation, Guangzhou, pp 630-635

Sayeef S, Rahman MF (2007) Comparison of proportional + integral control and variable structure control of interior permanent magnet synchronous motor drives. In: 38th IEEE power electronics specialists conference, Orlando, USA, pp 1645-1650

Senthil Kumar N, Sadasivam V, Asan Sukriya HM (2008) A comparative study of PI, fuzzy, and ANN controllers for chopper-fed DC drive with embedded systems approach. Electr Power Compon Syst 36(7):680-695

Utkin VI (1974) Sliding systems and their using by systems with variable structure. Nauka, Moskva

Yu-Sheng L, Wang X-W (2009) Sliding-mode repetitive learning control with integral sliding-mode perturbation compensation. ISA Trans 48(2):156-165

Zheng Z, Fadel M, Li Y (2007) High performance PMSM sensorless control with load torque observation. In: The international conference on "computer as a tool", EUROCON, Warsaw, pp 1851-1855

Zhuang X, Rahman MF (2003) Sensorless sliding mode control of an interior permanent magnet synchronous motor based on extended Kalman filter. In: IEEE international conference on power electronics and drive systems, pp 722-727 